\title{
The Paniya Tribes in Nilgiri Hills of Tamil Nadu
}

\section{S. Anandakumar ${ }^{1 *}$ and G. Ramakrishnan ${ }^{2}$}

\author{
'Part-time Ph.D., Research Scholar, School of Historical Studies, Madurai Kamaraj University, Madurai, Tamil Nadu, \\ India \\ ${ }^{2}$ Assistant Professor, Department of History, Saraswathi Narayanan College, Perungudi, Madurai, Tamil Nadu, India \\ *Corresponding author: anandsaduragiri7@gmail.com
}

Received: 09 Jan., 2020

Revised: 20 Feb., 2020

Accepted: 28 March, 2020

\begin{abstract}
Paniyans are one among the Primitive Tribal Groups (PTG's) in Tamil Nadu. The Paniyans or Paniyas are found in the Southern part of the India in the states of Tamil Nadu, Kerala and Karnataka. They are concentrated mainly in the Gudalur and Pandalur taluks of the Nilgiris district of Tamil Nadu. The Paniya are one of the five ancient tribal communities of Tamil Nadu. They dwell in different hill and forest areas of Tamil Nadu. Various districts where the Paniya tribes have built their settlements. Include Gudalur block and Pandalur Taluk. The detailed information about the origin of the Paniya tribe is still unclear, but some details relating to this tribal community signify a little about the extraction of this tribal group. Thick lips, dark complexion and curly hair are the physical appearance of the Paniya people.

According to 2011 census, the total population of the paniyans in Nilgiris district is 9,824 (4741 males and 5083 females). 36 Scheduled Tribes have been notified in Tamil Nadu by the Scheduled Castes and Scheduled tribes order (Amendment) Act 1976 and among them, six groups, namely, Paniyan, Todas, Kotas, Irulas, Kattunayakkan and Kurumbas are categorized as particularly vulnerable tribal Groups (PVTG) who are populated in Nilgiri District. Paniyas are the most important tribal community in Tamil Nadu among these sections. The Paniyas has very limited wants. Food, shelter and clothing are the only important wants of Paniyas. Better education facility, modern health system and variety of commodities in the market are not familiar with this community.

Paniyans as they are mostly landless laborers; illiterate, leaderless, unorganized and therefore generally unable to demand the minimum wages fixed by the Government. It is poverty and lack of self-respect that make the Paniyas willing tools in the hands of the clever crooks among the Nilgiri settlers. The Paniyas, as a whole, are the poorest of the poor among other tribal communities. Vast majority of the Paniyan work hard as coolies in tea estates and agricultural fields, from morning till evening, earn approximately ₹ 150 to 200 per day.
\end{abstract}


Paniyan Children hardly attend school. Most of the Parents do not take effort to send their children to school; they are not even ready to spend money to purchase school bags and stationeries for their kids.

The teachers in the elementary schools take effort to visit the settlements and bring the children to schools. At times the children hide themselves from teachers. Though they have got the provision of Tribal Residential Schools within few kilometers from the settlements, children often flee from attending school. The Paniyan is trying to retain their tribal character; changes are bound to persist in their traditional social organization, economic pursuit, political behaviour, etc., Consequents on the changes in all spheres a human thought and activity. Despite governmental efforts for their economic uplift, these tribal groups still continue to eke out a pathetic life in the midst of ignorance, indebtedness, ill- health and above all unhealthy economic practices.

Keywords: Settlements, Paniya, Tribal, Nilgiri, Primitive tribes, Population, Technology

The Tribe is the term used to describe certain human social groups most of the scholars dislike their term because it lacks a precise meaning and has been applied to many widely different groups. In addition, man of the people called tribes consider the term offensive or accurate. Most of them prefer such terms as ethnic groups. The European of the term described the people of these areas as tribes, though the groups varied greatly in their economic, political and social organization. Most of the Europeans reared the colonized peoples, whose technology was less advanced than theirs as primitive was. In time, the word tribe acquired the board meaning of primitive group. The tribal population is found in almost all parts of the world. Tribal's are called variously in different countries.

From the tribal community perspective Tamil Nadu can be broadly divided into two geographical divisions - the eastern coastline and the mountainous region in the north and west where a large majority of tribal people live. Western Ghats (Sahyadri hills) run southwards along the whole length of the western border of the state until they terminate at Kanyakumari which is the southernmost tip of the state and the country. Eastern Ghats originating in Orissa and passing through Andhra Pradesh enter Tamil Nadu and run across the districts of Thiruvannamalai, Salem and Coimbatore. They finally join the Western Ghats to form the Nilgiri Plateau where primitive tribes like Toda, Kurumba and Kota live.

The important hill groups like the Jawadhu hills and Yelagiri hills of Thiruvannamalai and Vellore districts, the Kalrayan hills of Villupuram and Salem districts, the Pachamalais, the Kollimalais and Yercaud ranges of Salem district, the Anaimalais of Coimbatore district, the Sitteri hills of Dharmapuri district, the Palani of Madurai district are an offshoot of either the Eastern or the Western Ghats. Malayali, Irula and Kurumans are the chief tribes inhabiting these hills. Coimbatore district is bounded on the north by the arm of Western Ghats over an area of 60 miles towards the east. This area consists of tall hills called Biligiri-Rangam and Hasanur hills on the Karnataka border and Burgur and Palamalai hills on the border of Salem district. On the west are the Velliangiri and Boluvampatti hills, which are 
an extension of the Western Ghats. on the south, another arm of the Western Ghats stretches from the Anaimalais on the border of Kerala and the Palani hills in Dindigal district. Irula, Sholaga and Malasar, are the chief tribes inhabiting these hilly areas. The Sitteri hills of Dharmapuri district are inhabited by Malayalis, Irulas and Kurumans. Palliyan, Pulayan and Muduvan tribes are found in the Palani hills of Dindigal district. Deep down south, Kaanikkar tribe live in the Districts of Kanyakumari and Tirunelveli.

The Nilgiris mountains are unique. They are formed at the junction of the ranges of the Eastern and Western Ghats, which run southwards at a converging angle in the state. These mountains which were endowed with thick valuable forests in the early $19^{\text {th }}$ century, are now transformed into tea and coffee plantations and rich cultivation fields for tribes like Toda, Kurumba, Kota, Irula and Paniya. Several non-tribal groups immigrated into the Nilgiri plateau reducing the tribal people to a minority group.

\section{Paniyas in Tamil Nadu}

Paniyas have a number of settlements in the Nilgiris district of Tamil Nadu. Their settlements are spread mainly throughout Gudalur taluk: in Mudanad, Cherangod and Namblakod Amshams of the Nilgiris districts. According to the 1991 census their total population in the Nilgiris of Tamil Nadu is 5700. It is believed that the Mandatan Chetties were the first to introduce them into Tamil Nadu. It is reported that the Paniyas were found in Gudalar taluk of Nilgiris district were brought over here long ago as agricultural labors by the Mandatan Chetties, from Wynad region of Kerala. Most of the Paniyas are employed in the agricultural farms owned by the Chetties. Many of them are employed as bonded servants. The Bonded labor System (abolition) ordinance was issued on October 24th, 1976 by the President of India. It was also made application to the Paniyas by the Government of Tamil Nadu. This order helped many bonded Paniya workers to be released from their masters and return to their own settlements. The government distributed lands to the released Paniyas in 1976 itself, after this many Paniyas became farmers in their own land. (Pfefer, Georg. 1997).

There are many voluntary organizations now working for the welfare of the Paniyas in Guladar taluk of the Nilgiris district, besides government agencies. Among them the following three contribute very much for their overall development. They are NAWA (The Nilgiris Adivasi Welfare Association) concentrating on medical and educational needs of the tribe. The second is S.S.S.S.S (Sree Saguru Sarva Samarasa Sangam) concentrating on the education of Paniyas children. The third is ACORD (Action for Community Organization, Rehabilitation and Development) and their work includes helping in agriculture, health, education and awareness programs.

Paniyas are spread throughout the state. Their distributions according to 2001 census report in the various districts are given in the following table. (India: Anthrological Survey of India.2011). The following table reveals that these days, many of them are found migrating to other parts of Tamil Nadu for the purpose of education and employment. Once upon a time their life was very much limited to a limited geographical location, now they are spread out to other parts of the country. Madras - 202 Chengal Pattu - 120 North Arcot - 82 South Arcot- 62 Dharmapuri - 90 Salam- 32 Nilgiris- 8500 Madurai - 50 Thanjavoor- 45 total $-9,183$. 


\section{Paniyas in Nilgiris}

The Nilgiris, because of its natural charm and pleasant climate, was a place of Special attraction for the Europeans. In 1818, Mr. Whish and Kindersley, who were assistants to the Collector of Coimbatore, discovered the place Kotagiri near Rengaswamy peak. John Sullivan, the then Collector of Coimbatore was greatly interested in this part of the country. He established his residence there and reported to the Board of Revenue on 31st July 1819.

The Name 'Nilgiris' means Blue hills (Neelam - Blue and giri - Hill or Mountain) the first mention of this name has been found in the Silappadikaram. There is a belief that the people living in the plains at the foot of the hills, should have given the name, the Nilgiris, in view of the violet blossoms of 'kurinji' flower enveloping the hill ranges periodically. The earliest reference to the political history of the Nilgiris, according to W.Francis relates to the Ganga Dynasty of Mysore.

Immediately after the Nilgiris was ceded to the British in 1789, it became a part of Coimbatore district. In August 1868 the Nilgiris was separated from the Coimbatore District. James Wilkinson Breeks took over the administration of the Nilgiris as its Commissioner. In February 1882, the Nilgiris was made a district and a Collector was appointed in the place of the Commissioner. On 1st February 1882, Richard Wellesley Barlow, who was the then Commissioner became the First Collector of Nilgiris.

The Nilgiris is situated at an elevation of 900 to 2636 meters above MSL. Its latitudinal and longitudinal dimensions being $130 \mathrm{KM}$ (Latitude : $10-38 \mathrm{WP} 11-49 \mathrm{~N}$ ) by $185 \mathrm{KM}$ (Longitude : $76.0 \mathrm{E}$ to 77.15 E). The Nilgiris is bounded on North by Karnataka State on the East by Coimbatore District, Erode District, South by Coimbatore District and Kerala State and as the West by Kerala State.

In Nilgiris District the topography is rolling and steep. About $60 \%$ of the cultivable land fall under the slopes ranging from 16 to 35\%. The Nilgiris District Comprises of six taluks viz Udhagamandalam, Kundah, Coonoor, Kotagiri, Gudalur and Pandalur. These taluks are divided into four Panchayat Unions viz., Udhagamandalam, Coonoor, Kotagiri and Gudalur besides two Municipalities, Wellington Containment and Aruvankadu Township. The District consists of 88 Revenue Villages and 15 Revenue Firkas. There are three Revenue Divisional in this district viz., Udhagai, Coonoor and Gudalur. There are 35 Village Panchayat and 11 Town Panchayat in this District.

The Nilgiri region is inhabited by the following tribal groups - the Paniya, Toda, Kota, Irula, , Kattunayaka, Mullu Kurumba, Urali Kurumba, and Jenu Kurumba, etc. All these communities were living in seen to represent the relationship with the forests of whose flora and fauna they had an intimate knowledge. The different tribal communities are present at different socio-economic levels by examining the occupation patterns and culture of some of these tribal ethnic groups over a period of time. It becomes clear how development and modernization have affected their lives.

\section{Paniyas / Paniyan}

The word 'Paniya' is derived from 'pani' which is a Malayalam word meaning work. Thus, the word 'Paniyan' literally means 'worker' or 'laborer'. The term 'Paniyan' is used for addressing males, whereas 
females are referred by them as 'Panichi. According to the census of India report, 1891 (Volume XIII, Madras), "Paniyan literally means a laborer, and the members of the Paniyan caste are agricultural laborer" Paniyans are a short, dark skinned tribe with broad noses and curly hair that they are popularly supposed to be of African descent based on their physical appearance but this is not to be established. The people of this tribal community are mostly laborers and their past history also suggests the same. In fact, the Paniya community is among those tribal peoples who have traditionally worked as bonded laborers. Thick lips, dark complexion and curly hair are the typical physical characteristic of the Paniya people. There is some resemblance between the Paniya people and African natives and some scholars are of the opinion that the Paniyas may be of African origin. According to some scholars, Kapiri (Africa or the Cape) is the land of origin of the Paniya tribes. The Paniya tribes are mainly concentrated in the northern part of the Western Ghats. Wage labour, small game hunting and collecting forest produce are the main means of living for this community. However, their movement within the forest has also been restricted by legislations designed to protect wildlife and biodiversity. Small scaletraditional mixed millet food farming is practiced which includes exclusive varieties of little millets and maize other than pulses, cereals, greens, vegetables and tubers.

According to 2011 census, the total population of the paniyans in Nilgiris district is 9,824 (4741 males and 5083 females). Generally believed that paniyans are of the Dravidian Tribes and they are the origin of Africans. The European planting community brought their ancestors to work in their estates in Malabar from Africa. But, it is not proved with sufficient facts. The paniyans are the most characteristic representatives of the Dravidian Tribe extended by the admixture of the Aryans, Scythians and Mongoloid elements. It is believed that their original occupation is Agriculture labour but they are also famous for hunting wild animals with spear and nets. Mostly paniyans are found to be very backward in Education and Economic status. They have been far away from the main stream of development. Most of them are found in the forests and Remote Hills.

Government of India categorized the paniyans as primitive tribes in constitution as scheduled tribes to give a special status and consideration. Paniyans have been in constant contact with the people of the surrounding communities. This influence leads them into many changes in their societies, beliefs and practices. The Industrialization and Urbanization also have played a remarkable role in the process of social transformation among the Primitive Paniyan Tribal Groups in India and Tamil Nadu.

In modern days many of the paniyans have been influenced by Urban Culture by their dress style, food habit, and socio-economic status. This study discusses about the present days life style of paniyans. It is based on one settlement to another settlement in appearance, socio and economic status of the paniyans and their living environment conditions. The paniyans in Tamil Nadu are mainly inhabitant in the Gudalur block of the Nilgiris district. By study the researcher bring out some facts about paniyans social structure. Most of their socio and economic aspects are linked with the Religion, Economic, Social and Environmental aspects of their life. Traditionally they live according to the environment of the forest and custom. 


\section{Backdrop of the Study}

Nilgiris hills dates back to $11^{\text {th }}$ and $12^{\text {th }}$ century. It was mentioned in Silapathikaran and was the part of the Kingdom like the Cholas, Pallavas and Hoysalas. Etymologically, the word 'Nilgiris' means 'Blue Mountains'. The name 'Neelagiri' was doubtless suggested by those living in the plains below them plateau by the blue haze that envelops the range as is common with most distant hills of considerable evergreen vegetation. Attributing the violent blossom of, strobe an-theses to the blue haze leading to the name 'Neelagiri' may be discounted on the fact that the plants are not so prevalent now-a-days and they blossom at long intervals, once in 12 years. But the mountains are still looking bluish from the plains. For many centuries the Tribes of the Nilgiri hills in South India were isolated from the people of the plains below. The steepness of the hills and the climate of the plateau discouraged any extensive contacts with the people close to Hindu life but culturally remote from it.

The Nilgiris constituency of Tamil Nadu has the largest proportion of Adivasi population in the Tamil Nadu, but rights activists worry that their vote carries very little weight. Tribals of Nilgiris are homogeneous and indigenous communities in India. Many of them are still live in a hills and forest region. They are called them Aboriginal, Adivasi and hill tribes, because they are living in the remote hills area. Adivasi - 'Adi' means oldest and 'vasi' means inhabitant is commonly used to designate them. The etymological the word 'Paniyan' is derived from pani which means work and literally meaning labour or workers. Majority of this community works as agricultural labourers. Thurston (1909) mentioned that when the coffee planters from outsider were settling in the area, they purchased settling in the area; they purchased land along with the Paniyan living there, and utilized their services.

Suitable referred as the Blue Mountains Nilgiri Hills is among the captivating hill stations in Tamil Nadu. Lying at an elevation of $2280 \mathrm{~m}$ above sea level, the hills beckon tourists to enjoy the splendour of nature. With its scenic landscapes, lush greenery and numerous slopes, Nilgiri hills attract tourists with its natural setting. The steep hills along with innumerable rivers and very small stream further enhance the appeal. The peaceful climate and the refreshing tea gardens are other highlights of the place.

\section{Statement of the Problem}

The present study is limited to the Paniyas of Nilagiri hills of Tamil Nadu only. Paniya are ancient inhabitant of Tamilnadu and follow own traditional religious customs and practices. They mostly live in the hill settlements the most common form of marriage among the Paniyas is marriage by negotiation. The local leadership of Kuttan or Muppan or Elder administration them. In this traditional system of religion is full of spirit worship, rites and rituals. They do not easily mingle with other tribal communities of these areas. The Paniyas usually avoid marrying their cross cousins. Monogamy is the most common form of marriage, among Paniyas whereas, polygamy form of marriage is also found in few settlements in the district. However, polyandry form of marriage is completely absent in Paniyan society. Levirate form of marriage is prevalent in both male and female. The members of the Paniyan community of Nilgiri district are tied together in groups by various types of bonds of which the linear decent and marriage ties are important. The types of relationship thus built up are as follows 1 . Consanguine one 
between parents, children and succeeding generation, and 2. A final relationship between spouses and their relatives on either side. The kinship terminology of the Paniyas may be divided mainly into two systems: (1) classificatory kinship and (2) Particularizing to descriptive kinship terms A few kinship reference terms are given below to understand kin relations consist of the interacting roles that are customarily ascribed to the different statuses of relationship by Paniyans. Many of them have adopted the religions of the surroundings like Hinduism. The paniya tribes are socially economically backward. So the researcher undertaken the study of socio-economic and cultural life of paniya tribes in present scenario.

\section{Aim of the Study}

To trace out the origin and development of the Paniya tribe of South India.

To study the socio-economic customs and cultural patterns of Paniyas tribes in Tamil Nadu.

To evaluate the traditional religious life of Paniyas and the changes taking place in their religious life.

To study the social changes due to contexts socio-political and environmental challenges like modernization, globalization, urbanization, etc.

The study also point out the various economic activities of paniyan tribes.

The Study out the Tourist attractions.

\section{Methodology and Sources Materials}

The present study is both historical and analytical in nature. It is descriptive yet at the same time analytical and interpretative. Apart from gathering data from the traditional archival sources, the scholar has adopted various techniques such as the field study, personal observation method and interviews to gather first hand information. Keeping in mind, the time constraints, the scholar has restricted the number of people interviewed. The people were interviewed based on a questionnaire.

The study is to be considering both primary and secondary sources. The primary Sources serve as the backbone of the torso of historical research. The chief research technique followed was participation. As participant observer, the researcher took part in a wide range of social activities of Tribals. After collecting first hand data, the researcher formulated a questionnaire to make this study more authentic and scientific. The secondary sources of data are collected from relevant books in different libraries.

\section{CONCLUSION}

Thus the study finds the importance of the Socio economic and cultural life of paniya tribal group in the villages of Nilgiris. There are 49 tribal communities throughout the state, out of which thirty six were scheduled tribes and the rest are unnoticed tribal communities. Among the tribal communities 
of Tamil Nadu not only differ from the non tribals but also from one another. Every district in Tamil Nadu has some tribal population. They are finding significantly in the districts of Nilgiris, Tharmapuri, Thiruvannamalai and Selam. These districts are having $80 \%$ of the tribal population in Tamil Nadu. In Nilgiri District also numerically large tribal community is Paniya. The main economic livelihood of the Paniya tribal community is their manual labour and there is not much diversity in their employment pattern and source of income. Their earning capacity is very low. Their income and standard of living too are correspondingly at very low level.

\section{References}

1. Behura, N.K. 2000. "Tribes of India: Planned Development", The challenges of Tribal Development, Published by Sarup \& Sons.

2. Abraham, Z. 1981. Ethno botany of the Todas, the Kotas, the Irulas of the Nilgiris. In: S.K., Jain (Ed.). Glimpses of Indian Ethno botany. Oxford \& IBH Publishing Company, New Delhi.

3. Hosagowder, V.B. and Hendry A.N. 1996. Ethno botany of the tribes Irulas, Kurumbar and Paniyas of the Nilgiris in Tamil Nadu Southern India, J. Econ. Tax. Bot. Addl. Ser.

4. Sashikumar, J.M. Karthikeyani, T.P. and Janardhanan, K. 2001. Traditional Phytocure for Paralysis among the Badagas of the Nilgiris, Tamil Nadu, Advances in PL.Sci.

5. Anthony King D. 1976. Colonial Urban Development, London.

6. Blanford., H.F. 1859. Survey Report M.JL.S. XV. 75, The Nilgiris.

7. Cryilnanmony, 2005. Dalits, and Tribes of India, New Delhi.

8. Devasahayam, N. 2006. The Tamil Nadu Tribes, Vol, XVI, Chennai.

9. $\quad$ Francis, W. 2002. The Nilgiris, Madras District Gazetteers, New Delhi.

10. Gopalakrishnan, M. 1995. The Nilgiris District Gazetteer, Madras.

11. Jakka Parthasarathy, 2007. Tribes \& inter ethnic relationship in the Nilgiri district, Tamil Nadu, Nilgiri.

12. Johan Friedrich Metz, 1864. The Tribes Inability the Nilgherry Hills: Social Customs and Religious Rites, Mangalore.

13. Ratnakker Bhencra, Bijoy, C.R. and Luithui, S. 1999. The Adivasis of India, An MRG International Report, Published by Texture.

14. Misra, S.K. 2019. Tribal Culture of India, An ITRHD Publication, New Delhi.

15. Bijoy, C.R., Gopalakrishnan, S. and Khanna, S., 2010. India and the Rights of Indigenous Peoples, Asia Indigenous Peoples Pact (AIPP), Thailand.

16. Balakrishnan, R. 1984. Nilgiri Mozhikal, All India Tamil Linguistic Association, Annamalai Nagar.

17. Geetha, V. and Chandramohan, P. 2011. A Handbook of Tribal Studies in Annamalai University, TSL Publisher, Chidambaram.

18. Thurston, E.1909. Castes and Tribes of Southern India, Vol. IV, Madras. 


\section{Government Orders:}

1. Tamil Nadu Rural Transformation Project, Tribal Development Plan, Economic Perspectives Centre for Data Research, April 2017.

2. G.O (Ms) No. 525, Social Welfare, Department dated: $27^{\text {th }}$ June 1980.

3. G.O (Ms) No. 983, Personnel and Administrative Reforms, Department dated: $7^{\text {th }}$ October 1986.

4. G.O (Ms) No. 44, Adi Dravidar and Tribal Welfare (TDL), Department dated: 20.05.1998.

5. G.O (Ms) No. 50, Adi Dravidar and Tribal Welfare (TD2), Department dated: 29.04.2009.

6. G.O (Ms) No. 6, Adi Dravidar and Tribal Welfare, Department dated: 09.01.2012.

7. G.O (Ms) No. 92, Adi Dravidar and Tribal Welfare, Department dated: 11.9.2012.

\section{Internet Reference}

1. https://nilgiris.nic.in/

2. https://nilgiris.nic.in/about-district/

3. https://nilgiris.nic.in/tourism/ 